\title{
Is there a dilemma for the truthmaker non-maximalist?
}

\author{
Alexander Skiles
}

Received: 1 October 2013 / Accepted: 4 May 2014 / Published online: 18 May 2014

(C) Springer Science+Business Media Dordrecht 2014

\begin{abstract}
Mark Jago has presented a dilemma for truthmaker non-maximalism-the thesis that some but not all truths require truthmakers. The dilemma arises because some truths that do not require truthmakers by the non-maximalist's lights (e.g., that Santa Claus does not exist) are necessitated by truths that do (e.g., that Barack Obama knows that Santa Claus does not exist). According to Jago, the non-maximalist can supply a truthmaker for such a truth only by conceding the primary motivation for the view: that it allows one to avoid positing strange 'negative' entities without adopting a non-standard account of the necessary features of ordinary things. In this paper, I sketch out and defend two plausible non-maximalist proposals that evade Jago's dilemma.
\end{abstract}

Keywords Truthmakers · Truthmaker non-maximalism - Metaphysical grounding · Negative existentials $\cdot$ Positive facts $\cdot$ Jago $\cdot$ Mellor

\section{Introduction}

Jago $(2012,2013)$ presents a dilemma for truthmaker non-maximalism: the thesis that some, but not all, truths require for their truth that a truthmaker exist. ${ }^{1}$ Jago specifically focuses on non-maximalist proposals according to which true 'negative' propositions, and in particular negative existentials like

(N) <Ern Malley does not exist $>$,

\footnotetext{
${ }^{1}$ Or at least requires a plurality of things that collectively make it true. I suppress this qualification throughout.
}

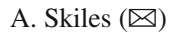

Institut de Philosophie, Université de Neuchâtel, Espace Louis-Agassiz 1, 2000 Neuchâtel, Switzerland e-mail: alexander.j.skiles@gmail.com 
require no truthmakers. ${ }^{2}$ Although these do not exhaust the non-maximalist proposals on offer, I will follow suit. ${ }^{3}$ After briefly laying out Jago's dilemma (§2), I will show that there are at least a couple plausible non-maximalist proposals with the resources to escape $(\S 3)$.

\section{Jago's dilemma for truthmaker non-maximalism}

Jago's dilemma arises for two reasons. Suppose that $\langle p>$ is one of propositions in the benighted class of truths that need no truthmaker. The first reason is that one can often find a factive operator ' $\mathrm{O}$ ' such that $\langle\mathrm{O} p\rangle$ is apparently a non-negative truth, one in need of a truthmaker even by the non-maximalist's lights. To use Jago's example, attaching the factive epistemic operator 'Max knows that' to a sentence expressing (N) yields a new sentence expressing the seemingly non-negative truth

$(\mathrm{KN})<$ Max knows that Ern Malley does not exist $>$.

The second reason why Jago's dilemma arises is that most non-maximalists also endorse truthmaker necessitarianism: the thesis that a thing makes $\langle p>$ true only if, necessarily, $\langle p>$ is true if that thing exists. For this is a key premise to motivating non-maximalism. There seems no 'garden variety' thing that can both make $(\mathrm{N})$ true and necessitate its truth. So one seems forced to either posit absences, totality facts, negative facts, or some other exotic specimen from the ontological zoo that necessarily excludes Ern Malley, or reject necessitarianism. According to the non-maximalist, one can avoid both options by rejecting that $(\mathrm{N})$ needs a truthmaker instead.

Against this backdrop, Jago proceeds by asking what the non-maximalist should say about $(\mathrm{KN})$, given what she says about $(\mathrm{N})$. He sets out three options, and argues that only the third is viable:

$i$. Suppose first that $(\mathrm{KN})$ is a negative truth. Since I will simply grant that $(\mathrm{KN})$ is not, I will pass over Jago's argument for this conclusion (2012, pp. 911-2).

ii. Suppose next that $(\mathrm{KN})$ is a derivative truth. Although $(\mathrm{KN})$ is not itself in need of a truthmaker, nonetheless its truth must ultimately "derive" from the truth or falsity of "logically more basic" positive propositions one can "analyse" it in terms of; the truth of $(\mathrm{KN})$ is then accounted for in terms of the existence or nonexistence of truthmakers for the positive propositions (KN) derives from (2012, p. 910; cf. Mellor 2003, 2009). Jago's objection to this option is that if there were such positive propositions, the conjunction of the true ones with the negations of the false ones would constitute an exceptionless sufficient condition for Max to know that Ern Malley does not exist. (I follow Jago in assuming that the truth of a derivative proposition is necessitated by the pattern of truth and falsity over the positive propositions it derives from, and grant him this inference.) Yet there

\footnotetext{
2 Following Jago, I assume that propositions exist and are bearers of truth, although nothing of substance is effected by taking sentences in contexts of utterance to be the bearers of truth instead.

3 For defence of this variety of non-maximalism, see Simons (2005), Mellor (2003; 2009) and Saenz (2014). Although I cannot survey the extent to which Jago's dilemma generalizes to other non-maximalist proposals here, it should become clear that the responses I offer generalize to the same extent.
} 
is strong inductive evidence that no such conditions are there to be found: "the extensive literature on the Gettier problem failed to find any" (2012, p. 912).

iii. (KN) is thus a positive truth, in need of a truthmaker. Let $\mathbb{T}$ be one of them. Since the truth of necessitarianism is assumed, it is impossible that both $\mathbb{T}$ exist and $(\mathrm{KN})$ not be true. Yet since 'Max knows that' is factive, it is impossible that both $\mathbb{T}$ exist and (N) not be true. But this can be so only if the existence of $\mathbb{T}$ necessarily excludes the existence of Ern Malley. Hence if $(\mathrm{KN})$ requires a truthmaker, then there must exist a thing that necessarily excludes the existence of Ern Malley, even by the non-maximalist's lights.

So: $(\mathrm{KN})$ has $\mathbb{T}$, an Ern Malley-excluding entity, as a truthmaker. But what kind of entity could $\mathbb{T}$ be, such that it does what it does? According Jago, the only strategies available to the non-maximalist for answering this challenge are just the familiar maximalist strategies. The non-maximalist can either bloat ontology with strange 'negative' entities like absences, totality facts, or negative facts, as some maximalists do ("ontology maximalists"). Or the non-maximalist can adopt a non-standard account of necessary features had by contingent 'garden variety' things that allows them to necessarily exclude each other, as other maximalists do ("necessity maximalists"). Either way, the non-maximalist loses her dialectical edge against the maximalist. Thus goes Jago's dilemma for the non-maximalist.

\section{Evading Jago's dilemma: two non-maximalist proposals}

How should the non-maximalist respond? My goal in this section is to sketch out two strategies, either of which alone is sufficient to evade Jago's dilemma.

\subsection{First non-maximalist proposal: positive facts about the truth of negative existentials}

The first proposal takes (KN) to be a positive truth, yet supplies it a necessitating truthmaker without positing any strange 'negative' ontology. According to this proposal, among the facts that collectively make $(\mathrm{KN})$ true, one must also include positive facts about the truth of negative existentials.

To keep matters simple, consider two such facts in particular. First, if (N) is true, then suppose there exists a certain positive fact about this truth: namely, that $<$ Ern Malley does not exist $>$ is true. Second, consider the following negative existential about which kind of epistemic situation Max is not in with respect to his justified belief about Ern Malley:

$(\mathrm{NG})<$ Max is not in a Gettier scenario $>$.

Max is in a Gettier scenario if, despite truly justifiably believing that Ern Malley does not exist, Max fails to know that this is so. ${ }^{4}$ Suppose, as with (N), that if (NG) is true,

\footnotetext{
${ }^{4}$ One can take this to be an compactly stateable sufficient condition for Max's being in such a scenario, or a massive disjunction of the possible scenarios in which he has been Gettiered. It will not matter for my purposes.
} 
then there exists a certain positive fact about its truth: namely, that $<$ Max is not in a Gettier scenario $>$ is true. (Jago presents no arguments against the non-maximalist's appealing to facts per se, nor against facts about abstract objects such as propositions. Even if this is problematic, Jago has supplied no reason for thinking so. As well, one can rephrase what is to come in terms of states-of-affairs, or tropes, or events, or..., so long as it supplies one with corresponding bits of reality taken to be distinct from the relevant negative existentials, yet that exist just when they are true.)

With these two positive facts about the truth of $(\mathrm{N})$ and $(\mathrm{NG})$ in tow, the nonmaximalist can now easily state what $\mathbb{T}$, the putative truthmaker for $(\mathrm{KN})$, is supposed to be-while invoking no absences, negative facts, or totality facts in the course of doing so.

$(\mathrm{KT}) \mathbb{T}$ is the collection consisting of the following three facts:

i. that Max justifiably believes that Ern Malley does not exist

ii. that <Ern Malley does not exist $>$ is true

iii. that $<$ Max is not in a Gettier scenario $>$ is true

Three comments before considering objections to $(\mathrm{KT})$. The first is that the facts picked out above are to be taken as 'worldly' and no less 'spooky' than as any other positive fact about abstract objects, and are clearly distinct from the propositions they have as constituents: although $<$ Ern Malley does not exist $>$ exists at worlds in which it is false, that <Ern Malley does not exist $>$ is true does not. The second is that the collection of facts listed above collectively necessitate the truth of (KN). Thus the proposal comports with necessitarianism. The second is that nothing essentially hinges upon taking that Max justifiably believes that Ern Malley does not exists to be included on this list, or upon it being exhaustive. If the proposed replacement or addition is a positive fact, then so long as it does not necessarily exclude the existence of Ern Malley, the proposal succeeds just the same. ${ }^{5}$ Other replacements or additions are handled by making use of still more positive facts about the truth of negative existentials (e.g., that $<$ Max does not justifiably believe merely by luck that Ern Malley does not exist $>$ is true, in place of that <Max is in a Gettier scenario $>$ is true).

Will $(\mathrm{KT})$ do the trick? The first objection I will consider is that despite what I claimed above, facts about the truth of negative existentials are not positive, and so $(\mathrm{KT})$ saddles the non-maximalist with negative ontology.

I have two replies to this first objection. The first is that its central claim seems implausible on its face. There could be three putative sources of 'negativity' here: the negative existential, truth itself, or the specific way in which the negative existential has its truth. But a negative existential is just a proposition, a 'positive' thing if any is. (It is of course true that a negative existential represents how things are negatively; but

\footnotetext{
5 I cannot fully survey which putative additions or replacements will do, but there are many attractive options. Any non-factive conception of belief possession that allows it to be reliably produced, or evidentially supported, or warranted, or undefeated, or to have arose out of an act of intellectual virtue, or..., even though the content of that belief be false, would do the trick. (As Jago notes (2012, p. 913), some proposed sufficient conditions for knowledge employ factive operators, for which the original problem re-emerges. Nonetheless my contention that at least some plausible non-maximalist proposals evade Jago's dilemma, which is all I set out to defend here, still holds. Moreover, see fn. 9 for a possible to way extend what I say to factive operator-involving conditions.)
} 
to then infer that a negative existential is itself a negative entity would be obviously fallacious.) Likewise, truth in general, and the manner in which a negative existential has truth in particular, seem to characterize how a proposition is, not how it fails to be-as intuitive a diagnostic for the 'positivity' of some characteristic as any (cf. Marshall 2009, p. 668). ${ }^{6}$ Appearances may be deceptive, of course. Yet it would bad for the would-be proponent of Jago's dilemma to have to develop an account of what it is for a fact to be negative- - a fortiori, one that classifies facts about truth in general, or about the truth of negative existentials in particular, as negative - in order to undermine $(\mathrm{KT})$. I suspect that there is no general account with such implications to be had, so I wish those who pursue this route good luck. ${ }^{7}$

My second reply is that most accounts of truth in general (and therefore of the truth of negative existentials in particular) do not imply that facts about truth are negative facts, and indeed some even entail that they are not. Now, the non-maximalist typically rejects accounts that analyze truth in terms of correspondence, utility, coherence, identity, or some plurality of these because they typically deny that the truth of a negative existential consists in how it stands to non-semantic reality (cf. Merricks 2007, ch. 7). All the same, few such accounts take truth to consist in the lack of something (or need to do so, in any case). And accounts of truth more amenable to the non-maximalist such as Horwich's (1998) minimalism or Merricks's (2007) primitivism deny that there is anything substantive to say about a proposition characterized by truth, and thus deny that a true proposition is characterized by how it fails to be. So the proposal under consideration does not face any threat from background theorising about the nature of truth either.

Another kind of objection concedes that facts about the truth of negative existentials are positive. The objection now is that since the existence of that $<$ Ern Malley does not exist $>$ is true necessarily excludes the existence of Ern Malley, the non-maximalist has thereby lost her dialectical edge against the ontology maximalist by appealing to it.

This second objection has two serious flaws. The first is that the non-maximalist never claimed such a dialectical edge in the first place. Jago's challenge, recall, was not that $(\mathrm{KN})$ has a truthmaker that necessarily excludes the existence of Ern Malley. Now, some non-maximalist reject truthmakers for negative existentials for this reason (e.g., Lewis 1992, 2003), but others have few qualms with them. ${ }^{8}$ Rather, the original challenge for the non-maximalist was to explain how (KN)'s truthmaker could necessarily exclude the existence of Ern Malley without appealing to the familiar maximalist strategies. Given that $(\mathrm{KT})$ does no such thing, that challenge is met.

\footnotetext{
6 To be sure, a negative existential is extrinsically true - at least insofar as its truth holds at least partially in virtue of how things 'external' to it stand. But a thing's positive characteristics can also be extrinsic (e.g., my owning a cat).

7 Barker and Jago (2012) develop a theory of negative facts that takes them to be non-mereological complexes of objects and properties in which the former "anti-instantiate" the latter, with negative properties lambda-abstracted from these. But I see no particularly compelling reason why any of the facts that (KT) leans on must be conceived of as the product of a negative existential's anti-instantiating falsity, or its anti-instantiating either-falsity-or-indeterminacy, or its anti-instantiating anything else for that matter.

8 E.g., those who take 'tropes', 'modes', or 'moments' as truthmakers-particularized properties like the redness of Max's desk at one time, or its greenness at another-take them to be necessary excluders (cf. Mulligan et al. 1984).
} 
The second flaw with this objection-even if one insists that positing the existence of an Ern Malley-excluding entity remains intrinsically problematic-is that the non-maximalist still retains her dialectical edge. There is of course a well known philosophical puzzle in the neighbourhood. But it is a puzzle shared by ontology maximalist and non-maximalist alike: namely, that of explaining how $<$ Ern Malley does not exist $>$ could be a truth just when Ern Malley does not exist. This is simply an instance of the traditional problem of negative existentials that Quine (1961) called "Plato's Beard": how could there be any truths about what does not exist if their subject matter does not exist? But solutions to this problem automatically explain how the existence of that $<$ Ern Malley does not exist $>$ is true necessarily excludes Ern Malley_since necessarily, this fact exists if and only if this negative existential is true. And luckily for the non-maximalist, these solutions need not (and typically do not) invoke negative ontology. ${ }^{9}$ The non-maximalist retains a dialectical edge because the ontology maximalist bears the additional perplexities brought along with the negative ontology she invokes anyway-negative ontology that the non-maximalist has no need for.

The third and final objection I will consider can be stated in the form of a dilemma. ${ }^{10}$ It begins with a question: is a fact like that $<$ Ern Malley does not exist $>$ is true a fundamental fact? If the answer is no, then the proposal under consideration seems to be committed to producing something that the non-maximalist claims not to be there: something that somehow accounts for the truth of a negative existential. And yet if the answer is yes, the proposal under consideration seems to be committed to an immense plethora of fundamental facts, at least two for every true statement of knowledge about a negative existential. One might object to this plethora for any number of reasons: one might reject a profligate fundamental level for general considerations of parsimony, for instance, or one instead might follow Jonathan Schaffer and complain that "[s]emantic facts, such as the fact that a given proposition bears a certain truthvalue, are just the wrong sort of thing to be fundamental" (Schaffer (2008), p. 308). Therefore, the proposal seems to be either incompatible with non-maximalism, or else takes on board a problematic plethora of fundamental semantic facts.

Fortunately for the non-maximalist, the dilemma can be resisted along either horn. Against the first horn, it would be problematic for the non-maximalist to take the truth of negative existentials as non-fundamental if the only way to 'account for' the truth of a proposition entails supplying it with a truthmaker. However, it has become standard among non-maximalists to note that another way to 'account for' its truth is by characterizing what it is metaphysically grounded in (non-causally holds in

\footnotetext{
9 Of course, some solutions claim that there is no such proposition as <Ern Malley does not exist $>$, and others claim that this proposition is false; if either one of these two solutions is correct, then there is no fact as that $<$ Ern Malley does not exist $>$ is true, but obviously Jago's dilemma goes away as well. Representative solutions accept that this proposition exists and is true, and that have no trace of negative ontology, include Braun (1993) among many others. These solutions also appear to extend in a natural way to factive operators analysable in terms of truth under a selection of ways the world could have turned out to be, such as Sosa's (1999) notion of safety and Williamson's (2000) notion of a most general factive mental state. Given the modest aim of this paper (see fn. 5) I will not pursue the issue further here.

10 Thanks to Fabrice Correia, Michaela McSweeney, Noël Saenz, and an anonymous referee for independently pressing me to address versions of the following objection.
} 
virtue of), which need not involve supplying truthmakers. ${ }^{11}$ The most straightforward way to do so is by introducing the ontologically non-committal sentential operator "...because..." which, when combined with a pair of sentences " $p$ " and " $q$ ", yields a truth-evaluable grounding statement. By means of this operator, one can state general principles about how the truth of a certain class of propositions gets grounded. A well-known principle that traces back to Aristotle is that the truth of any proposition gets grounded in how things are with regards to its subject matter:

(A) If $\langle p\rangle$ is the proposition that $p$, and $\langle p\rangle$ is true, then $\langle p\rangle$ is true because p. $^{12}$

If (A) is true, then every fact about the truth of a proposition is grounded, and thus every fact about the truth of every negative existential is non-fundamental. Nonetheless, claims of this logical form do not entail that " $p$ " refers to a thing-a fact-nor $a$ fortiori that the existence of the alleged thing that " $p$ " refers 'accounts for' the truth of $\left\langle p>\right.$. ${ }^{13}$ There is no tension, then, between denying that negative existentials have truthmakers, yet still taking their truth to be non-fundamental.

Against the second horn - that treating the truth of negative existentials as fundamental would for some reason or other cause trouble for the non-maximalist- the best I can do is point the reader to recent work by Baron et al. (2013), Kristie Miller, and James Norton: although "no friends" of the view, after considering an array of potential sources of trouble they "reluctantly" conclude that none of them withstand critical appraisal (2013, p. 193).

\subsection{Second non-maximalist proposal: derivation clauses for propositions employing factive operators}

The only palpable cost with the first non-maximalist proposal, then, is ontological: it helps itself to a plenitude of positive facts about truth. Some non-maximalists are willing to pay the price (or already have); what about the rest? Rather than taking (KN) to be a positive truth requiring a truthmaker, the second proposal instead takes $(\mathrm{KN})$ to be a derivative truth, itself lacking a truthmaker, yet whose truth is ultimately connected with the existence or non-existence of truthmakers for certain positive propositions which the truth of $(\mathrm{KN})$ ultimately derives from. The proposal is straightforward; moreover, the Gettier problem does not bear on it at all.

\footnotetext{
11 Versions of the non-maximalist strategy that I will now outline can be found in Correia $(2005, \S 3.2)$, Melia (2005), Schnieder (2006) and Merricks (2007) among others.

12 "When is what is called truth or falsity present, and when is it not? We must consider what we mean by these terms. It is not because we think that you are white, that you are white, but because you are white we who say this have the truth. (Metaphysics 9, 1051b, 5-8 [1984, pp. 1661]; cf. Categories 14b, 15-22 [Aristotle (1984), pp. 22]).

13 What if, following Rosen (2010), one takes grounding statements to ascribe a relation? Then the suitability of the strategy I have outlined turns on what one takes the relata of this relation to be. For instance, the non-maximalist could not follow Audi (2012) and take the relata of grounding to be 'worldly' particulars partially individuated by the objects they have as constituents, since the non-maximalist denies that there is a worldly particular with Ern Mally as a constituent. However, the strategy can be adopted by the non-maximalist if she instead follows Rosen and takes the relata of grounding to be true propositions; see McGrath (2003) for defense.
} 
Jago does not say much about the nature of the relevant relation of derivability. But he assumes that a derivative truth must be logically analyzable in terms of the positive propositions it derives from, via repeated applications of the following clauses (2012, p. 108):

[A] true conjunction $<\mathrm{A} \& \mathrm{~B}>$ derives its truth from the truth of both $<\mathrm{A}>$ and $<\mathrm{B}>$; whereas a false conjunction $<\mathrm{A} \& \mathrm{~B}>$ derives its falsity from the falsity of either $<\mathrm{A}>$ or $<\mathrm{B}>$. Similarly, a true disjunction $<\mathrm{A} \vee \mathrm{B}>$ derives its truth from the truth of either $<\mathrm{A}>$ or $<\mathrm{B}>$, whereas a false disjunction $<\mathrm{A} \vee \mathrm{B}>$ derives its falsity from the falsity of both $<\mathrm{A}>$ and $<\mathrm{B}>$. A true negation $<\neg \mathrm{A}>$ derives its truth from the falsity of $<\mathrm{A}>$, whereas a false negation $<\neg \mathrm{A}>$ derives its falsity from the truth of $<\mathrm{A}>$.

The truth of a derivative proposition is then connected with the presence or absence of truthmakers for those positive propositions (ibid., fn. 11):

For positive propositions $<\mathrm{A}>,<\neg \mathrm{A}>$ 's truth is derivative on $<\mathrm{A}>$ 's lacking a truthmaker and $<\neg \mathrm{A}>$ 's falsity is derivative on $<\mathrm{A}>$ 's having a truthmaker.

But the non-maximalist is free to reject such an overly narrow conception of derivability. Nothing precludes her from also making use of derivation clauses that are sensitive to the subject matter of the truth - not just its logical form - and to then take the truth and falsity of the positive propositions to serve merely as the metaphysical ground for its truth, not its reductive basis.

Indeed, she is free to make use of accounts of this sort already found in the truthmaker literature. For instance, here is a brief sketch of how a account of derivation can be connected up with a more general theory of truthmaking inspired by the theory developed by Cameron (forthcoming), who is incidentally no non-maximalist. In Cameron's theory, the only truthmakers are what make brute pure existence claims true: a claim is brute if it is an ungrounded proposition, and a pure existence claim if expressible by sentences of the form "the $x$ s exist" (where "the $x \mathrm{~s}$ " rigidly designates one or more things; p. 5). Let $\Pi$ be the set of brute truths. Let $\Sigma$ be the set of pure existence claims. And if $\langle p\rangle$ is a proposition of the form $\langle<q\rangle$ is false $>$ for any proposition $<q>$, let $<p>\in \mathcal{F}(\Sigma)$ iff $(i) \quad<q>\in \Sigma$ and (ii) $<p>$ is true; i.e., $\mathcal{F}(\Sigma)$ is the set of all true propositions about which pure existence claims are false. The theory is then stated via four claims.

Claim \#1: $\Pi$ is a subset of $\Sigma \cup \mathcal{F}(\Sigma)$.

Claim \#2: Every truth is either in $\Pi$, or collectively grounded in the members of some subset of $\Pi$.

Claim \#3: $<p>$ is made true by the $x \mathrm{~s}$ iff either $<p>$ is the proposition that the $x$ s exist and $<p>\in \Pi \cap \Sigma$, or there are some $<q_{1}>,<q_{2}>, \ldots \in \Pi \cap \Sigma$ that collectively ground $\langle p>$ and collectively say that the $x$ s exist.

Claim \#4: $<p>$ is a derivative truth iff $<p>$ is true and there are no $x$ s that make $<p>$ true.

(A full theory of derivation would be equipped with principles regarding which propositions ground which that are sensitive to their logical form and subject matter. I take 
them to include at least those mentioned by Jago in the quoted passage; however, I lack the space to explore what other principles ought to be added.)

Working now within this broader conception of derivability, the derivation clauses that the non-maximalist can now apply to truths about knowledge should now be obvious. They can be read off from the positive facts offered up by the first nonmaximalist proposal we considered. Applied to $(\mathrm{KN})$, they are simply the following:

(DK) The truth of $<$ Max knows that Ern Malley does not exist $>$ collectively derives from the truth of the following three propositions:

(JN) <Max justifiably believes that Ern Malley does not exist $>$

(N) $<$ Ern Malley does not exist $>$

(NG) $<$ Max is not in a Gettier scenario $>$

Applying the logical derivation clauses to (DK), the non-maximalist can then connect the truth of $(\mathrm{KN})$ with the existence or non-existence of truthmakers for positive propositions with ease. $(\mathrm{JN})$ is a positive truth that possesses an Ern Malley-compatible truthmaker. The negative truths (N) and (NG) derive their truth from the falsity of the positive propositions they are negations of: namely $<$ Ern Malley exists $>$ and $<$ Max is in a Gettier scenario $>$. The truthmakers for these two positive propositions do not exist. Therefore, the truth of $(\mathrm{KN})$ is ultimately accounted for by the existence of a truthmaker for $(\mathrm{JN})$ and the non-existence of truthmakers for the negations of both (N) and (NG). ${ }^{14}$

But wait-didn't the Gettier problem teach us that exceptionless sufficient conditions for one to know are unlikely to be found (p. 912)? How, then, were we able to produce some so easily? The reason is that the Gettier problem taught us no such thing. To solve the Gettier problem, it is not enough to produce just any exceptionless sufficient conditions for knowledge. (That is easy; the truth of a proposition is an exceptionless sufficient condition for the truth of itself.) Rather, the problem is to produce exceptionless sufficient conditions conditions that can also be crafted into an informative analysis of knowledge. But as was emphasized above, (DK) purports to do no such thing. For the non-maximalist's purposes, there may be no way to specify what it is for Max to be in a Gettier scenario in a finitely stateable way and without re-invoking the notion of knowledge. That would of course be a threat to (DK)'s serviceability in an informative analysis of knowledge. But it is no a threat to its serviceability to the non-maximalist, whose aim is the more modest one of connecting this truth about Max's knowledge with the existence or non-existence of truthmakers for a specific collection of positive propositions.

Or at least not obviously a threat. Although Chudnoff (2011) similarly distinguishes between the project of informatively analyzing versus metaphysically grounding truths about knowledge, he also argues that inclusion of an 'anti-Gettier' condition such as

\footnotetext{
14 It is important to remember that on the Mellor-style conception of derivability under consideration, what is being claimed here is not that $(\mathrm{KN})$ is ultimately made true in part by facts about the non-existence of truthmakers for the negations of (N) and (NG). For strictly speaking, (KN) has no truthmaker at all (cf. Mellor 2003, p. 213). Rather, the task for the "sophisticated" non-maximalist as Jago calls her (p. 910) is merely to provide the truth conditions for $(\mathrm{KN})$ purely in terms of the existence or non-existence of truthmakers for certain positive propositions, and thereby perspicuously link the truth of (KN) to what's in one's ontology and what isn't. (KN), I claim, provides the means to do this.
} 
(NG) into the metaphysical ground of $<$ Max knows that Ern Malley does not exist $>$ renders it either "vacuous" or "just too heterogeneous", and doing so in turn "renders it unable to contribute toour understanding of why this truth? [this proposition about Max's knowledge] obtains". But even if Chudnoff is correct that (NG) is unable contribute to our understanding of this truth obtains (which is certainly not obvious), it is a matter of considerable controversy whether metaphysical grounding bears an intimate link with explanatory understanding. Viable theories of metaphysical grounding do not all presuppose one (cf. Audi 2012; Schaffer 2012).

\section{Conclusion}

I have offered the non-maximalist two proposals to choose from, both of which allow her to retain a dialectical edge over the maximalist. The first made use of positive facts about negative existentials. The second utilized a broader conception of how derivative truths derive their truth from positive propositions, one that made use of metaphysical grounding rather than logical analysis. Since both proposals are attractive, and either one is sufficient, I conclude that the non-maximalist has more than she needs to evade Jago's dilemma. ${ }^{15}$

\section{References}

Aristotle. (1984). In J. Barnes (Eds.), The compete works of Aristotle (vols. 1-2). Princeton: Princeton University Press.

Audi, P. (2012). Grounding: Toward a theory of the in-virtue-of relation. Journal of Philosophy, 109, 685-711.

Barker, S., \& Jago, M. (2012). Being positive about negative facts. Philosophy and Phenomenological Research, 85, 38-117.

Baron, S., Miller, K., \& Norton, J. (2013). Groundless truth. Inquiry, 57, 175-195.

Braun, D. (1993). Empty names. Noûs, 27, 449-469.

Cameron, R. (forthcoming). Truthmakers. In M. Glanzberg (Ed.), The Oxford handbook of truth. Oxford: Oxford University Press. http://www.personal.leeds.ac.uk/ phlrpc/truthmakers\%20handbook\%20truth. pdf.

Chudnoff, E. (2011). What should a theory of knowledge do? Dialectica, 65, 561-579.

Correia, F. (2005). Existential dependence and cognate notions. Munich: Philosophia Verlag.

Horwich, P. (1998). Truth (2nd ed.). Oxford: Oxford University Press.

Jago, M. (2012). The truthmaker non-maximalist's dilemma. Mind, 121, 903-918.

Jago, M. (2013). The cost of truthmaker maximalism. Canadian Journal of Philosophy, 43(4), 460-474.

Lewis, D. (1992). Critical notice of D. M. Armstrong's a combinatorial theory of possibility. Australasian Journal of Philosophy, 70, 211-224.

Lewis, D. (2003). Things qua truthmakers. In Lillehammer, H., \& Rodríguez, G. (Eds.), Real metaphysics: Essays in honour of D. H. Mellor (pp. 212-238). London: Routledge.

Marshall, D. (2009). Can "Intrinsic" be defined using only broadly logical notions? Philosophy and Phenomenological Research, 78, 646-672.

\footnotetext{
15 I wish to thank Paolo Bonardi, Alexander Bown, Pablo Carnino, Fabrice Correia, Ghislain Guigon, Michaela McSweeney, Robert Michels, Kevin Mulligan, Noël Saenz, Maria Scarpati, and anonymous referees for their comments and encouragement. This article was completed while funded by the Swiss National Science Foundation as a member of the research project "The Nature of Existence: Neglected Questions at the Foundations of Ontology" (ID \#: 10012_150289), and I am grateful for its generous support.
} 
McGrath, M. (2003). What the deflationist may say about truthmaking. Philosophy and Phenomenological Research, 66, 666-688.

Melia, J. (2005). Truthmaking without truthmakers. In H. Beebee \& J. Dodd (Eds.), Truthmakers: The contemporary debate (pp. 67-84). Oxford: Clarendon Press.

Mellor, D. H. (2003). Replies. In Lillehammer, H., \& Rodríguez, G. (Eds.), Real metaphysics: Essays in honour of D. H. Mellor (pp. 212-238). London: Routledge.

Mellor, D. H. (2009). Truthmakers for what? In H. Dyke (Ed.), From truth to reality: New essays in logic and metaphysics (pp. 272-290). New York: Routledge.

Merricks, T. (2007). Truth and ontology. Oxford: Oxford University Press.

Mulligan, K., Simons, P., \& Smith, B. (1984). Truth-makers. Philosophy and Phenomenological Research, 44, 287-321.

Quine, W. V. O. (1961). On what there is. In From a logical point of view: Nine logico-philosophical essays (2nd ed, pp. 1-19). New York: Harper and Row Publishers.

Rosen, G. (2010). Metaphysical dependence: Grounding and reduction. In B. Hale \& A. Hoffman (Eds.), Modality: Metaphysics, logic, and epistemology (pp. 109-134). Oxford: Oxford University Press.

Saenz, N. (2014). The world and truth about what is not. The Philosophical Quarterly, 64(254), 82-98.

Schaffer, J. (2008). Truth and fundamentality: On Merricks' truth and ontology. Philosophical Books, 49, $302-316$.

Schaffer, J. (2012). Grounding, transitivity, and contrastivity. In F. Correia \& B. Schneider (Eds.), Metaphysical grounding: Understanding the structure of reality (pp. 122-138). Cambridge: Cambridge University Press.

Schnieder, B. (2006). Truth-making without truth-makers. Synthese, 152, 21-46.

Simons, P. (2005). Negatives, numbers, and necessity: Some worries about Armstrong's version of truthmaking. Australasian Journal of Philosophy, 83, 61-253.

Sosa, E. (1999). How to defeat opposition to Moore. Philosophical Perspectives, 13, 53-141.

Williamson, T. (2000). Knowledge and its limits. Oxford: Oxford University Press. 